\title{
Emerging Technologies for Developing Cross-Cultural Competency
}

\author{
https://doi.org/10.3991/ijet.v14i21.11194 \\ Galina Pudikova ${ }^{(凶)}$ \\ Peoples' Friendship University of Russia (RUDN University), Moscow, Russian Federation \\ galina.pudikova368@gmail.com
}

Anastasia Kurilova

Togliatti State University, Togliatti, Russian Federation

Vasily Movchun

Federal State Autonomous Educational Institution of Higher Education I.M. Sechenov First Moscow State Medical University of the Ministry of Health of the Russian Federation (Sechenov University), Moscow, Russian Federation

Elena Medvedeva

Far Eastern Federal University (FEFU), Vladivostok, Russian Federation

Galina Kochetkova

South Ural State University, Chelyabinsk, Russian Federation

\begin{abstract}
In the context of globalization, cross-cultural competence plays a significant role in professional development. This study performs a survey among 650 university students in the area of linguistics. The survey reveals that students understand the importance of cross-cultural competence and that it is developable though online programs. However, they are not always ready to develop cross-cultural competence using formal solutions. To solve this problem, several options are suggested like (1) changing the strategy and methods for improving cross-cultural competence; (2) offering additional sources of information on cross-cultural topics; (3) creating online forums for communication with international students; (4) raising interest in online conferences; and (5) designing in-house programs for the online development of cross-cultural competencies.
\end{abstract}

Keywords-Online technologies; cross-cultural communication; language competence; student survey; multicultural education; intercultural communication competence.

\section{Introduction}

People have entered an era of unprecedented electronic information age with the extensive application and advanced development of economic globalization, integra- 
tion of the world, and modern information technology. This phenomenon has increased the demand for highly qualified talents with skilled foreign language communication competence and thus has raised requirements for talent cultivation. That is why one of the ultimate goals of foreign language teaching in universities is to cultivate students' intercultural communication competence, that is, the competence in the practical application of language [1]. With the development of society, there are more and more international communications, especially in English. Therefore, adding some reasonable and relevant cultural knowledge in University English will contribute to communicating in natural and native-like English [2].

Studies in the field of intercultural communication are more relevant today than ever due to increased global mobility and accessibility of technologies that facilitate intercultural contacts between different continents [3]. Therefore, it is wise to consider with due diligence the broader meaning of what we explore, publish and teach. One of the most important factors of successful intercultural communication is, without a doubt, a sufficient cross-cultural competence [4].

Intercultural communication has been categorized as an explicit content of the English syllabus for English and non-English majors. Accordingly, improving information technologies has begun to receive extensive attention from foreign language circles. However, most teachings and studies regarding the cultivation of crosscultural competence are studies on micro-level problems at the theoretical level [5]. In general, cross-cultural competence can be defined as the ability to empower individuals to be effective and communicative in intercultural contexts based on the intercultural knowledge, skills, and attitudes of an individual. In literature, interculturally competent individuals have the capability to learn foreign cultures, perspectives and approaches; to work with people from other cultures; to adapt to life in other cultures and know how to communicate with foreign colleagues [6]. However, the competence level varies between people: some of them seem to do better and achieve better results in the intercultural context. Although individuals may possess the necessary skills, knowledge and attributes to perform effectively in a cross-cultural setting, it might still find it difficult to achieve a high level of effectiveness in the face of the environmental barriers that challenge international business operations [7].

There is a rapid and important relationship between intercultural communication and social media with globalization. Some authors propose a real-time communicative teaching model, including the determination of communication topic, networking with communicative objects, implementation of communication based on the topic, and cultural analysis and summarization. However, this approach did not include an analysis of learning outcomes [8].

Cross-cultural sensitivity is identified as a decisive factor to successful working and living in a cross-cultural setting. Significant investments of time and resources may be put at risk if this factor is ignored. It is not enough for employees to simply have their stay abroad in their resumes to provide any measure of intercultural competence. Such people are often isolated from local cultures and their stay abroad strengthens, rather than softens, their sense of cultural insularity and superiority [9]. Cross-cultural sensitivity is a crucial variable in a variety of situations, which require interaction with people from other cultures, ranging from job performance during 
international assignments to tourism, immigration, and refugee resettlement. It is suggested that this quality is a key predictor of success in intercultural contexts [10].

Multimedia technologies broaden the capabilities of intercultural communication, diversify the models and types of intercultural communication, expand its functions, and reduce the barriers to intercultural communication gradually [11]. Wang and Zhaokuan focused on the theoretical aspect of multimedia technology on intercultural communication, but ignored the empirical side of research.

Later on, scientists analyzed the characteristics and advantages of multimedia network teaching methods in teaching. In college English teaching, teachers should not only pay attention to the listening, speaking, reading, writing, and translation skills of students but also make full use of the advantages of the network and strive to cultivate the sensitivity of students to cultural differences and foster cross-cultural competence in students [12].

Online discussion is a powerful tool for the development of critical thinking, collaboration, and reflection and has several benefits for participants of the discussion. The nature of discussion groups on the Internet makes them free from time and place restrictions. This location independence ensures that courses are available to students around the world. When the construct of cross-cultural participants is added to the existing challenges of facilitation in an online environment, the problems are intensified. Cultural problems such as linguistic misunderstandings, misunderstandings of cultural context cues, and online participation differences can be added to the list of online facilitative challenges.

In the business sphere, organizations globalize due to economic, political and market expansion and the workforce diversity increases. In this climate, organizational strategies that focus on developing employees who are effective in cross-cultural work settings are in increasingly high demand [13]. Cross-culturally savvy employees are essential in coordinating and liaising with foreign affiliates both within and outside the organization. For example, a growing number of organizations are relocating top and middle managers to work in countries other than their home country [14] requiring sophisticated cross-cultural interaction skills. In addition to globalization, the workforce has also become increasingly diverse in terms of race, ethnicity and nationality even within an organization situated in its home country. This workforce diversity highlights the importance of fostering employees' cross-cultural skills even if they do not plan to work in an international company in the future [15].

Thus, cross-cultural competence plays a significant role in the modern world and therefore must be taken into account when teaching students of different majors. Meanwhile interactive technologies are tightly connected with the education process and because of this connection, it is necessary to utilize them to develop a crosscultural competence.

The objectives of this study are to:

- Conduct an intercultural communication survey among students;

- Identify online programs that universities can utilize to develop the cross-cultural competence; 
- Formulate recommendations for the development of cross-cultural competence and for the utilization of associated online programs.

\section{$2 \quad$ Method}

\subsection{Research design}

To achieve research objectives, an empirical study was performed using a student survey for data gathering. The quantitative analysis is selected as a method for data collection and processing.

\subsection{Participants}

The survey involves a purposive sample of 650 full-time bachelor students $(66 \%$ female and $34 \%$ male, aged 20 to 21 ). The survey took place at four universities.

Table 1. Students Enrolled in the Survey

\begin{tabular}{|c|c|l|}
\hline No. of Students & Age & \multicolumn{1}{|c|}{ University } \\
\hline 177 & $20-21$ & The Peoples' Friendship University of Russia \\
\hline 198 & $20-21$ & The Higher School of Economics \\
\hline 125 & $20-21$ & The Moscow State Institute of International Relations \\
\hline 150 & $20-21$ & The Lomonosov Moscow State University \\
\hline
\end{tabular}

The first university in the survey is the Peoples' Friendship University of Russia, which provided a total of 177 students for the survey. All of them are Linguistics majors. The second university is the Higher School of Economics, which provided 198 students majoring in "Foreign Languages and Intercultural Communication." The third university is the Moscow State Institute of International Relations. The survey involves 125 students from this institute; they are students of "Translation, CultureOriented Linguistics and Cross-Cultural Communication". The last university is the Moscow State University. There, 150 students were enrolled at the Faculty of Foreign Languages and Area Studies.

\subsection{The participant's selection criterion}

The survey involves only students who are trained in the area of linguistics because the subject of cross-cultural competence is the most relevant specifically to them. In addition, these participants are fourth-year students, as senior students represent a workforce with the most potential and are ready to enter the labor market. At this stage of training, students have completed most of the courses in their field alongside practical training. They also have more experience in intercultural communication. 


\subsection{Research instruments}

A student survey is applied to identify the attitude of students to intercultural communication and its role in making a successful career. The questionnaire is broken up in two sections.

Section 1 consists of 9 closed questions.

The first question is aimed at identifying the level of familiarity with the very concept of cross-cultural or intercultural communication. The second question assesses the students' awareness of the importance of intercultural communication.

Since each and every student does not have the opportunity to receive intercultural knowledge through direct communication with native speakers (e.g., in travels), it is important that the university provides as much information as possible about the countries that speak the studied languages. The third question assesses the delivery of this information in the university setting.

The following question is somewhat related to the third one and assesses the contribution of teachers to the enhancement of students' cross-cultural competence.

Students of language must undoubtedly possess a high level of cross-cultural competency, as they interact with foreigners directly. However, this skill can find use in other areas, as many companies cooperate across cultures. The fifth question investigates what students think about cross-cultural competency in other professional fields.

The following question encourages students to express their opinions regarding the demand for employees with high cross-cultural competence among employers. This question is in the list because companies may cooperate internationally.

The respondents are asked to assess if sufficient cross-cultural competence is developable without a direct contact with the culture of another country and though online programs.

The last 9th question provides insight into whether the university sets up extracurricular activities for intercultural communication.

Section 2 offers several options for the online development of cross-cultural competence. These options are composed in a table as answers to a multiple answer question. Among them:

- University forums as one of the most accessible ways to enhance cross-cultural competence. Forums enable communication with representatives of other countries, who attend the same university as the native students attend, and allow students to learn about the new course content, communicate with teachers in an informal setting, etc.

- Thematic communities in social networks, in both Russian and other language. Online communities allow students to gain intercultural knowledge in a less formal setting. In addition, members of such a community collect different kinds of information about different cultures, which also improves the cross-cultural competence.

- Thematic apps and websites. They allow students to communicate with foreigners. Most often, such websites offer language classes and because they call for communication, language-teaching services allow mutual exchange of cultural knowledge and the development of communicative competence. 
- Online conferences. Participating in events that increase cross-cultural awareness provides an opportunity to improve academic performance and, in general, the ability to treat learning material.

- Online training also has a positive effect on the development of cross-cultural competence. Students may receive the necessary information and ask questions about issues of concern. This opportunity adds relevance to the knowledge gained.

- Live chat sessions with representatives of other cultures. Unlike informal communication via websites and apps, chat sessions are a way to improve cross-cultural competence through the interaction with specially invited "guests", who introduce their culture.

\subsection{Research issues and restrictions}

The study involves only fourth-year students and only students, who study in the field of linguistics. Moreover, the study takes place exclusively in the universities of Russia, which inhibits the identification of a problem on a larger scale. Thus, challenges identified in the study are relevant only to this group of respondents and related recommendations may be applicable only them.

Further research may imply a study with first-year to master students for progress assessment and to draw broader conclusions. In addition, similar studies may be performed with the participation of other faculties.

\subsection{Data analysis}

Data from the filled-out questionnaires is processed using the STATISTICA software package that allows visualizing data during statistical analysis. The error is $2 \%$ (13 questionnaires have unanswered questions).

\section{Results}

The first question reveals a positive trend in communication awareness: 98 percent of respondents indicate familiarity with the concept of cross-cultural communication. A rather large portion of respondents, 87 percent, agreed that cross-cultural knowledge plays a crucial role in building necessary communication with foreigners. Since students are familiar with the concept of intercultural communication, the associated skills are likely placed on the front burner of learning priorities.

Sixty-three percent note that information about non-native speaking countries that is provided in school and university textbooks is not sufficient to form a proper level of cross-cultural competence. This suggests that common textbooks are rather superficial and cannot be utilized to achieve cross-cultural communication of sufficient quality.

Eighty-five percent claim the awareness-improving capability of the teaching mode. Thus, students believe that the existing teaching methods and styles provide them with the necessary knowledge in the field of intercultural communication. This 
percentage value can be considered positive, since, despite the possible lack of information in the textbooks, the faculty puts effort to develop a decent level of crosscultural competence.

On the fifth question, responses prove to be positive as well. Sixty-nine percent of respondents agree on that knowledge in the field of cross-cultural communication is a requirement for specialists in fields other than linguistic. This suggests that students are aware of the phenomena like globalization and international cooperation.

Somewhat surprisingly, the overall response to the following question is less positive. Only $51 \%$ agree that an employer is more likely to hire someone with experience in intercultural communication. However, this result may come from the fact that there are still companies without international connections and they hire employees with experience that is not necessary cross-cultural.

The overwhelming majority of 92 percent note that for the full-fledged crosscultural communication, knowledge gained within the walls of an educational establishment may not be enough and requires real experience of intercultural communication. From this, it follows that students are not only aware of the importance of high cross-cultural competence but also understand that its development is not possible through the theory alone.

Many respondents, $63 \%$, admit the likelihood of cross-cultural competence development through different online programs. This may indicate that they are aware of and maybe put various interactive methods into practice to enhance cross-cultural competence.

On the last question, however, the trend goes from positive to negative, as only $40 \%$ of students indicate the existence of online platforms launched by their universities to ensure interaction between students. Thus, the development of cross-cultural competence in universities is not sufficiently enhanced.

The second section of the survey asks students to choose the most efficient, in their opinion, ways to improve cross-cultural competence online. The pie chart below presents the results. 


\begin{tabular}{|c|c|}
\hline Eniversity forums & " Thematic communities in social networks \\
\hline ECommunication websites & = Apps for language learning and cu tural exchange \\
\hline Enline conferences & Online training \\
\hline
\end{tabular}

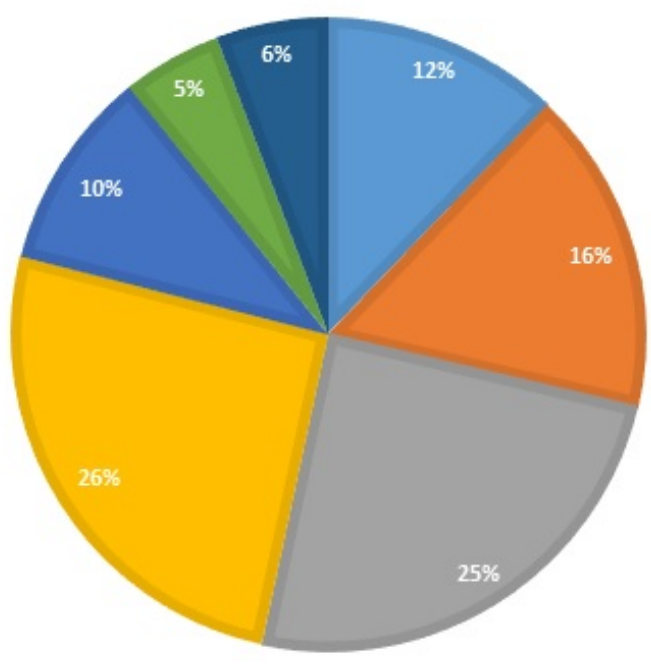

Fig. 1. Ways to Improve Cross-Cultural Competence

Table 2. Survey Results, Section 2

\begin{tabular}{|l|c|}
\hline \multicolumn{1}{|c|}{ Ways to Improve Cross-Cultural Competence } & No. of Answers \\
\hline Online forums & 294 \\
\hline Thematic communities in social networks & 402 \\
\hline Communication websites & 600 \\
\hline Apps for language learning and cultural exchange & 621 \\
\hline Online conferences & 250 \\
\hline Online training & 123 \\
\hline Live chat sessions & 138 \\
\hline
\end{tabular}

It is seen from the chart and the table that the most popular answers are "communication websites" and "apps".

Students view the informal exchange of intercultural experience as the most comfortable way to interact, as evidenced by the high score obtained for "thematic communities in social networks". By contrast, options that provide for the formal presentation of information gain few positive vote. In this light, we face a problem in that students need both forms of communication (formal and informal) to improve crosscultural competence. Providing balanced and specially prepared information also plays a significant role, as this provides students with a proper theoretical framework. 


\subsection{Strategies and methods for intercultural competence development among students}

An approach to the improvement of cross-cultural competence requires a certain degree of consistency. The development strategy should be clearly planned both by students and by teachers. First, students must realize the importance of intercultural communication. They also need to understand how a decent level of cross-cultural competence assists in career building. This is why cross-cultural competence is best to develop in school by gradually delivering the information about cultures of non-native speaking countries.

\subsection{Additional sources of information}

From this study, it becomes obvious that Russian students believe that textbooks provide an insufficient amount of information necessary for the development of crosscultural competence. Because some students are restricted in real intercultural communication (e.g., travel inability, the lack of non-native speaking friends, etc.), one of the main tasks of a teacher is to provide as much information about non-native speaking countries as possible. This information can be provided both in class and online.

\subsection{Online platforms/forums for communication with international students}

Online platforms (forums) are one of the most effective and convenient e-learning tools that allow cultural exchange alongside the development of a language competence. The obligation to create and launch such a platform rests entirely upon the university administration, as this process requires material costs. Online platforms are created with the participation of teachers and methodologists who provide useful recommendations. These platforms or forums may contain links to resources of interest and video materials (i.e., lectures, seminars, training videos). In the forum, students can search for the information they need and communicate with students from other countries. This is crucial for those who are unable to travel abroad or apply their skills of cross-cultural communication in any other way. Discussion forums allow students to develop their language skills and exchange cultural experiences.

\subsection{Online conferences}

Despite the fact that students demonstrate interest in the use of e-learning methods, they focus mostly on tools associated with informal communication. To receive balances information, students may want to participate in official online conferences or interviews with representatives of other cultures. Organizing such events is not enough and university administration should raise the interest of students in them. A voluntary participation and aspiration contribute to a better assimilation of material and, consequently, level the cross-cultural competence up. 


\subsection{In-house programs for online competence improvement}

In cooperation with programmers and with sufficient funding, universities are able to design their own online programs or websites to improve the level of cross-cultural communication. The design can stand on both the needs of students and general demands for education. In addition, universities may attract international partners to improve the effectiveness of their software.

\section{Discussion}

In the light of cooperation across cultures, cross-cultural communicative competence becomes a matter of importance and there are numerous studies devoted to it. Among them, a U.S. study condensed in 2013. In this study, 361 participants completed an online survey containing the newly developed cross-cultural PsyCap items. All participants were over the age of 18 and had previous work experience. A total of $71.2 \%$ of participants had either a four-year college degree or a graduate degree. The participants were reasonably balanced in terms of gender but with a slightly larger number of males $(61.2 \%)$. The ethnic distribution was fairly diverse in that $70.6 \%$ were Asian/Pacific Islanders, 26.6\% were Caucasian and $2.7 \%$ were of other ethnicities including Native American, Hispanic and African American. In terms of citizenship, $68.7 \%$ of the participants were from India, $26.3 \%$ were from the USA and the other 5\% were from diverse countries, including Germany, Poland, Austria, South Africa and the Philippines. As the survey was administered in English, all participants had to be fluent in English in order to take the survey [16].

The goal was to validate the newly developed cross-cultural PsyCap scale using a large and diversified sample of participants from different countries, cultures and various levels of international experience. Thus, the intent was to include participants of different demographic backgrounds to ensure the external validity of cross-cultural PsyCap as a generalizable measure of cross-cultural skills [17].

To assess the higher-order structure of cross-cultural PsyCap, a confirmatory factor analysis (CFA) is conducted via the AMOS 19 software. Specifically, authors examine whether the overall cross-cultural PsyCap exists as a second-order factor and whether it explains the relationships among the four lower order factors, namely, cross-cultural hope, optimism, self-efficacy and resilience, using the AMOS maximum likelihood procedure [18].

Results indicate the predictive validity of cross-cultural PsyCap that adds new constructs (e.g., ethnocentrism, openness) to the prediction of cross-cultural adjustment [19]. In particular, it was found that cross-cultural PsyCap explains an additional $5.4 \%$ of the variance in cross-cultural adjustment above and beyond the traditionally assessed cultural variables. In other words, cross-cultural PsyCap, while related to other constructs as predicted in the nomological network, captures unique nonoverlapping aspects of human capital and thereby adds to our general understanding of cross-cultural skills [20]. Therefore, the cross-cultural PsyCap includes unique aspects that are not captured by other variables, which adds to its predictive ability. It is possible that the unique aspects of cross-cultural PsyCap lie in its four-factor struc- 
ture emphasizing complementary psychological resources rooted in the theoretical foundations of positive PsyCap. Unique aspects of cross-cultural PsyCap include effective goal-setting strategies (cross-cultural hope) and the capability to overcome challenges (cross-cultural resilience) [21].

Another study, conducted in 2018, identified the relationship between the progress in cross-cultural competence development and the interactive materials that teachers utilize. The subjects of this study were second-year students at the Harbin University of Science and Technology. The experimental group consisted of 124 students in Class 16-A2 (major in Mechanics), Class 16-B4 (major in Computer Science), and Class 16-C1 (major in Measurement). For the reliability of the experiment, the control group selected 124 students from Class 16-A1 (major in Mechanics), Class 16-B3 (major in Computer Science), and Class 16-C2 (major in Measurement). The teaching mode for cultivating cross-cultural competence in college English based on modern information technology was used on the subjects to conduct a teaching experiment for one semester.

The study adopted interviews to investigate the satisfaction of students with college English courses and used pre-experimental questionnaires and post-experimental questionnaires to examine the level of cross-cultural competence. The questionnaire measured the variables and were designed on the basis of the skills, attitudes, and knowledge of language users. It consisted of 40 questions, and the total score was 100 points. The test of knowledge was divided into intercultural knowledge and communicative knowledge; the test of skills was divided into language skills and social communicative skills; and the test of attitudes was divided into the attitude toward national culture and attitude toward non-national cultures [22].

Results suggest a specific technology-based method to improve the cross-cultural competence of students in a college English class. Authors conclude that a teaching mode plays a significant supporting role and improves the teaching effect, degree of recognition of the curriculum among students, and the cross-cultural competence of students. The teaching mode overcomes the limitations of time and space, creates rich and real situations of intercultural communication, provides rich teaching and learning resources, effectively supplements in-class learning materials, effectively expands extracurricular learning, and achieves mobile teaching and learning [23]. The teaching mode organically integrates the language learning and cultural learning of students and develops the cross-cultural competence and language communication skills. Thus, students become dynamic and active cultural knowledge builders instead of static and passive knowledge receivers [24]. Interactivity satisfies the communication requirements of students for future work, improves their interest in learning, increases their cultural input, enhances their intercultural awareness and knowledge, and improves the language application and self-learning competencies of students [25].

In addition, with the use of online services (e.g., QQ, WeChat, Skype, MSN, etc.), students become able to develop intercultural communication and teachers receive the opportunity to enhance the application of different technologies in practice [26]. 


\section{Conclusion}

The cross-cultural competence plays a crucial role in professional development.

The survey of 650 fourth-year (bachelor) students in the area of linguistics, who represent a workforce with the most potential and perceive the cross-cultural competence as a requirement, proves that students understand the importance of crosscultural competence and consider it developable through online programs. However, it is proven that students are not always ready to develop intercultural competence using formal solutions. To solve this problem, several options are suggested.

First, make students realize the importance of intercultural communication. To achieve awareness, develop cross-cultural competence at the early age. Russian students believe that textbooks provide an insufficient amount of information necessary for the development of cross-cultural competence. Therefore, one of the main tasks of a teacher is to provide as much information about non-native speaking countries as possible. This information can be provided both in class and online. Utilize online platforms or forums, as they are one of the most effective and convenient e-learning tools that allow cultural exchange alongside the development of a language competence. In such forums, students can search for the information they need and communicate with students from other countries.

Hold online conferences or interviews with representatives of other cultures and raise students' interest in participating these events. A voluntary participation and aspiration contribute to a better assimilation of material and, consequently, level the cross-cultural competence up. In cooperation with programmers and with sufficient funding, design your own online programs or websites to improve the level of crosscultural communication.

These undertakings may serve as a framework for other universities both in Russia and abroad to conduct their own research on the role of cross-cultural competence in the context of building an international dialogue. In addition, the outlined elements of a learning infrastructure apply to specialists in different fields.

\section{$6 \quad$ References}

[1] Bingzhuan, P. (2018. Study on Cultivation of Intercultural Communication Competence of College English Based on Modern Information Technology. International Journal of Emerging Technologies in Learning, 13(09). https://doi.org/10.3991/ijet.v13i09.8724

[2] Zhao, X., Gu, S., Yu, S., Gao, M. (2016). College English teaching design and practice based on cross-cultural theory. International Journal of Emerging Technologies in Learning (iJET), 11(08): 65-70. https://doi.org/10.3991/ijet.v11i08.6051

[3] Dörnyei, Z., Csizér, K. (2005). The effects of intercultural contact and tourism on language attitudes and Tourism on Language Attitudes and Language Learning Motivation, Journal of Language and Social Psychology, 24(4):327-357. https://doi.org/10.1177/0261927 $\underline{\mathrm{x} 05281424}$

[4] Lantolf, J. P. (2000). Socio-cultural theory and second language learning. Oxford, UK: Oxford University Press. 
[5] Greenholtz, J. (2000). Assessing Cross-cultural Competence in Transnational Education: The Intercultural Development Inventory. Higher Education in Europe, 25(3): 411-416. https://doi.org/10.1080/713669273

[6] Adler, N. J., Bartholomew, S. (1992). Academic and professional communities of discourse: Generating knowledge on transnational human resource management. Journal of International Business Studies, 23: 551-569. https://doi.org/10.1057/palgrave.jibs.8490279

[7] Shafranov-Kutsev G.F., Efimova G.Z., Semenov M.Y. (2018). Career Guidance Practices Under the Conditions of Globalisation: a Sociological Analysis. The Education and science journal, 20(8): 46-65. https://doi.org/10.17853/1994-56392018-8-46-65

[8] Belz, J.A. (2003). Linguistic Perspectives on the Development of Intercultural Competence in Telecollaboration, Language Learning \& Technology, 7(5): 68-117.

[9] Zhang, B., Zheng, W. (2003). Cross-cultural awareness. Beijing: Tsinghua University Press, pp. 47-50.

[10] Xiao, W., Chen, X., Chen, M., Liao, R. (2013). Developing cross-cultural competence in Chinese medical students. Medical Teacher, 35(9): 788-789. https://doi.org/10.3109/0142 159x.2013.786178

[11] Wang, J., Zhaokuan, M. (2014). Survey of Information Technology Promoting Cultural Teaching from the Perspective of Integration. Modern Educational Technology, 24(4): 1922.

[12] Popova N.G., Biricheva E.V., Beavitt T.A. (2018). Three Aspects of the Phenomenon of Science: In Search for Unity among Sociologists. The Education and science journal, 20(9): 35-55. https://doi.org/10.17853/1994-5639-2018-9-35-55

[13] Ang, S., Inkpen, A.C. (2006). Cultural Intelligence and Offshore Outsourcing Success: A Framework of Firm-Level Intercultural Capability. Decision Sciences, 39: 337- 358. https://doi.org/10.1111/j.1540-5915.2008.00195.x

[14] Hechanova, R., Behr, T.A., Christiansen, N.D. (2003). Antecedents and Consequences of Employees' Adjustment to Overseas Assignment: A Meta-Analytic Review. Applied Psychology: An International Review, 52: 213-236. https://doi.org/10.1111/1464-0597.00132

[15] Suutari, V. (2003). Global Managers: Career Orientation, Career Tracks, Life-Style Implications and Career Commitment. Journal of Managerial Psychology, 18: 185-207. https://doi.org/10.1108/02683940310465225

[16] Dollwet, M., \& Reichard, R. (2013). Assessing cross-cultural skills: validation of a new measure of cross-cultural psychological capital. The International Journal of Human Resource Management, 25(12): 1669-1696. https://doi.org/10.1080/09585192.2013.845239

[17] Clapp-Smith, R., Luthans, F., and Avolio, B.J. (2007). The Role of Psychological Capital in Global Mindset Development. The Global Mindset: Advances in International Management, London: Emerald, pp. 105- 130. https://doi.org/10.1016/s1571-5027(07)19005-7

[18] Peterson, S.J., Byron, K. (2008). Exploring the Role of Hope in Job Performance: Results From Four Studies. Journal of Organizational Behavior, 29: 785- 803. https://doi.org/10. $1002 /$ job.492

[19] Lindell, M.K., Whitney, D.J. (2001). Accounting for Common Method Variance in CrossSectional Research Designs. Journal of Applied Psychology, 86: 114-121. https://doi.org/10.1037//0021-9010.86.1.114

[20] Gosling, S.D., Rentfrow, P.J., Swann, W.B. (2003). A Very Brief Measure of the Big-Five Personality Domains. Journal of Research in Personality, 37: 504-528. https://doi.org/10. $\underline{1016 / \mathrm{s} 0092-6566(03) 00046-1}$

[21] Luthans, F., Youssef, C.M., Avolio, B.J. (2007). Psychological Capital: Developing the Human Competitive Edge. New York: Oxford University Press. 
[22] Zhong, H., Fan, W. (2013). The Theoretical Framework for the Construction of Measuring Tools for Cross-cultural Communication of Chinese College Students. Foreign Language Education in China, 6(3): 19-28.

[23] Ouirdi M. El, Segers, J., El Ouirdi, A., Pais, I. (2015). Predictors of job seekers' selfdisclosure on social media. Computers in Human Behavior, 53: 1-12. https://doi.org/10.10 16/j.chb.2015.06.039

[24] Persell, C. H. (2004). Using focused web-based discussions to enhance student engagement and deep understanding. Teaching Sociology, 32 (1): 61-78. https://doi.org/10.1177/ $\underline{0092055 \times 0403200107}$

[25] Peng, S. (2007). Cross-cultural Sensitivity: Comparison between English Majors and NonEnglish Majors, Journal of Ningxia University (Humanities \& Social Sciences Edition), 29(1): 171-176.

[26] Starcic, A.J., Barrow, M., Zajc, M., Lebenicnik, M. (2017). Students' Attitudes on Social Network Sites and their Actual Use for Career Management Competences and Professional Identity Development, 12(5): 65-81. https://doi.org/10.3991/ijet.v12i05.6778

\section{Authors}

Galina Pudikova - fourth year PhD student, General and Russian Linguistic Departament, Philological Faculty, Russian Language Department № 1 of Faculty of Russian language and General Educational Disciplines, Peoples' Friendship University of Russia (RUDN University), Moscow, Russian Federation. Pudikova.g.n@gmail.com

Anastasia Kurilova - PhD, Professor, Department of Finance and Credit, Togliatti State University, Togliatti, Russian Federation.

Vasily Movchun - Candidate of medical science, Assistent of professor, Medical and Preventive Faculty Department of Surgery, Federal State Autonomous Educational Institution of Higher Education I.M. Sechenov First Moscow State Medical University of the Ministry of Health of the Russian Federation (Sechenov University), Moscow, Russian Federation.

Elena Medvedeva - Assistant Lecturer, The Academic Department of English Language, Far Eastern Federal University (FEFU), Vladivostok, Russian Federation.

Galina Kochetkova - has PhD degree in Pedagogy, Associate Professor, Computational Mechanics department, South Ural State University, Chelyabinsk, Russian Federation.

Article submitted 2019-07-04. Resubmitted 2019-08-25. Final acceptance 2019-08-29. Final version published as submitted by the authors. 


\section{Appendix}

Table 3. Questionnaire Sample

\begin{tabular}{|c|c|}
\hline Question & Answer Option \\
\hline \multicolumn{2}{|c|}{ Section 1. Cross-Cultural Communication in a University Setting } \\
\hline Are you familiar with the concept of cross-cultural communication? & $\begin{array}{l}\text { Yes } \\
\text { No }\end{array}$ \\
\hline $\begin{array}{l}\text { Is it possible without a due cross-cultural competence to build a } \\
\text { meaningful interaction with a representative of another culture? }\end{array}$ & $\begin{array}{l}\text { Yes } \\
\text { No }\end{array}$ \\
\hline $\begin{array}{l}\text { Do university and school textbooks deliver sufficient information } \\
\text { about the non-native speaking countries? }\end{array}$ & $\begin{array}{l}\text { Yes } \\
\text { No }\end{array}$ \\
\hline $\begin{array}{l}\text { Does the teaching mode increase your awareness in the field of } \\
\text { cross-cultural communication? }\end{array}$ & $\begin{array}{l}\text { Yes } \\
\text { No }\end{array}$ \\
\hline $\begin{array}{l}\text { Do specialists in non-linguistic fields need skills of cross-cultural } \\
\text { communication? }\end{array}$ & $\begin{array}{l}\text { Yes } \\
\text { No }\end{array}$ \\
\hline $\begin{array}{l}\text { Are employers more likely to hire an individual with the cross- } \\
\text { cultural experience? }\end{array}$ & $\begin{array}{l}\text { Yes } \\
\text { No }\end{array}$ \\
\hline $\begin{array}{l}\text { Is the university incapable of fostering a necessary level of cross- } \\
\text { cultural competence or is there a need for direct communication } \\
\text { with foreigners, for traveling, etc.? }\end{array}$ & $\begin{array}{l}\text { Yes } \\
\text { No }\end{array}$ \\
\hline $\begin{array}{l}\text { Is it possible to improve cross-cultural competence through online } \\
\text { programs? }\end{array}$ & $\begin{array}{l}\text { Yes } \\
\text { No }\end{array}$ \\
\hline $\begin{array}{l}\text { Does your university have an online platform for communication } \\
\text { with other students including international students? }\end{array}$ & $\begin{array}{l}\text { Yes } \\
\text { No }\end{array}$ \\
\hline \multicolumn{2}{|c|}{ Section 2. Ways to Improve Cross-Cultural Competence } \\
\hline $\begin{array}{l}\text { What instruments from the following improve the cross-cultural } \\
\text { communicative competence? }\end{array}$ & $\begin{array}{l}\text { Online forums; } \\
\text { Thematic communities in social } \\
\text { networks; } \\
\text { Communication websites; } \\
\text { Apps for language learning and cul- } \\
\text { tural exchange; } \\
\text { Online conferences; } \\
\text { Online training; } \\
\text { Live chat sessions. }\end{array}$ \\
\hline
\end{tabular}

